\title{
Whole Object Assumption and Mutual Exclusivity Assumption in 3-4-Year-Old Cebuano Preschoolers: A Qualitative Analysis
}

\author{
Daylinda Luz R. Laput \\ De La Salle University - Manila \\ daylinlaput@gmail.com
}

\begin{abstract}
The whole object assumption (WOA) and mutual exclusivity (ME) assumption proposed by Markman (1990) are constraints children use in word learning. This small-scale psycholinguistic study investigates the constraints function in 14 preschoolers at ages 3 and 4 using WOA and ME in deciphering part labels. Using quasi-experimental method, children identified objects and animals. Findings show that while WOA is still used by the participants ME overrides. Further findings reveal no evidence of the claim that older participants used ME better than the younger ones. However, gender seems to play an important role in the participants' performance for boys did much better than girls in the experiments. Thus, the result recommends further future research on the relation between the two constraints on word learning (WOA and ME) and age and gender. However, this study found two limitations: the drawings and the questions used in the study may fail to fully reveal the children's ability since previous studies offer non-standard materials and procedure used in their experiments; and the study itself, is regarded as small-scale. Therefore, the research findings can hardly be generalized. Nevertheless, the research at least presents how the Cebuano speaking preschoolers learned new words via WOA and ME assumption.
\end{abstract}

Keywords: whole object assumption, WOA, mutual exclusivity, ME, preschoolers 


\section{INTRODUCTION}

Children acquire words at a tremendous speed in spite of the difficulty of the tasks. Dromi (1987) documented a study on individual child's vocabulary acquisition, revealing an acquisition rate of 45 words per week (in Markman, 1990, p.57). The finding concurs with Carey's (1978) reported calculations that by age six, children have learned 19,000 to 14,000 words, roughly about nine words a day from about 18 months on. Various hypotheses have been presented, among which the most influential are the hypothesis proposed by Piaget et al $(1964,1966)$ and that by Markman et al (1990).

Inhelder and Piaget (1964) and Bruner, Olver, and Greenfield (1966) implicitly held some form of a model which traditionally explains how children form categories and acquire category terms. And this model is to assume a kind of general, all-purpose, inductive mechanism. This view about how categories are acquired contains many implicit assumptions about the nature of categories, about the way in which they are learned, and about how children's abilities to categorize change with development (in Markman, 1990, 57). These theories assume that concept learning begins by the learner encountering a positive exemplar of the category, from which the learner formulate a tentative hypothesis about what the criteria might be that define the category. But, reformulating hypotheses in the face of negative evidence is not a trivial problem and children up until six or seven have been shown to have great difficulty in dealing with all but the simplest kinds of hypotheses. In sum, even 6-year-olds have trouble solving these kinds of inductive problems, yet 2-year-olds are very successfully solving the inductive problems involved in acquiring new terms (Markman, 1990, p. 58). These young children must, therefore, acquire terms in ways that do not require sophisticated, logicaldeductive, hypothesis testing (Dromi, 1987; Markman and Wachtel 1988; Markman, 1990).

Since the hypothesis proposed by Piaget et al seems not working in explaining children's amazing achievement in word learning, Markman et al proposes another hypothesis, which assumes that children learn words via at least three constraints on word meaning: the whole-object assumption, the taxonomic assumption and the mutual exclusivity assumption.

A series of research, experimental or observational, has been conducted on the whole object assumption and mutual exclusivity assumption among children of different ages. Xu, Cote, and Baker (2005) proposed that a rudimentary version of the mutual exclusivity constraint may be functional among 12-month-old infants. Markman, Wasow and Hansen (2003) carried out three experiments among 18-20month-olds and found that lexical constraints enable babies to learn words even under non-optimal conditions --- when speakers are not clear and referents are not visible. Hansen and Markman (2009) made mutual exclusivity available to 2-yearolds and 3-year-olds by showing them familiar whole objects with novel parts and unavailable by showing unfamiliar whole objects with novel parts and found that both groups learned more part labels when mutual exclusivity was available. Charlotte (2009) tested the use of whole-part juxtaposition and mutual exclusivity in 3-4-year-old children with familiar and non-familiar objects. While most of the 
studies were conducted among English-speaking children, Go and Miraflores (2009) researched on effects of joint reference and mutual exclusivity on the application of whole-object assumption in Filipino 3-4-year-old preschoolers.

These studies provide evidence for the function of the whole object assumption and mutual exclusivity assumption at different levels and among different age groups. However, it seems that the academic interest is insufficient in34-year-old preschoolers in the non-metropolitan context in the Philippines. Besides, some of the studies aforementioned seem to be based on rather limited data. For example, there are 10 participants in Go and Miraflores' (2009) research and 4 in Charlotte (2009) study. Also, some of the findings in the research mentioned but not further studied the possible influence of gender in the use of the whole object assumption and mutual exclusivity assumption (Go and Miraflores, 2009). This present study aims to fill this gap by answering the following research questions:

1. What primary function do 3 to 5 year old preschoolers employ in learning new words?

2. In what instances does the mutual exclusivity assumption override the whole object assumption?

3. How do preschool children differ in the overriding function of ME in terms of age and gender?

\section{THEORETICAL FRAMEWORK}

The three constraints children place on word meanings proposed by Markman (1990) serves as the theoretical framework of the study. The whole object assumption refers to children's expectation that a novel label is likely to mean the whole object and not to its parts, substance or other properties (Carey, 1988, Mervis, 1987, as cited in Markman 1990, p. 59). The mutual exclusivity assumption (Markman, 1990) or the principle of contrast (Clark, 1983) refers to the children's expectation that a new term should refer to an object for which they do not have a label yet. The taxonomic assumption states that children regard novel labels as referring to objects of the same kind rather than to objects that are thematically related. The whole object assumption can be overridden by either taxonomic assumption or mutual exclusivity assumption under certain circumstances.

\section{RESEARCH METHOD}

\subsection{Research Design}

This study uses a quasi-experimental method to investigate children's use of whole object assumption and mutual exclusivity assumption in naming and identifying objects and animals. This is in nature a small-scale investigation in children's use of whole object assumption and mutual exclusivity assumption in deciphering part labels. The specific interest was the description of children's use of whole object assumption and mutual exclusivity assumption in deciphering novel parts of given objects. 


\subsection{Participants and setting}

Participants of the study were 14 Cebuano speaking preschoolers with equal number in both age groups and genders. Of the 7 preschoolers at the age of three, 4 were boys and 3 were girls; of the 7 preschoolers at the age of four, 3 were boys and 4 were girls. Thus, the factors of age and gender were under control in the sampling of the participants. In order to ensure a comfortable environment for the participants, 13 out of the 14 data gathering cases were conducted in the house of these children, and the other 1 was carried out in a birthday party all in Dipolog City, province of Zamboanga del Norte, Philippines. A pilot testing of the materials and procedures was conducted with a child at the age of 3 who was not a participant of the study a week before the data gathering.

\subsection{Instrument}

Two sets of colorful drawings were used in the study. The first set of instrument is a drawing of an object with a mutually exclusive different part, to be specific, a table with one of the legs as a horse's leg. The second set of instrument consists of four drawings of animals with mutually exclusive different parts, one being a pig whose head has horns of a carabao, the other being a fish with a lizard's tail, another being a butterfly whose other wings are leaves and the last is an elephant with a beak attached instead of its long nose and a mouth (see Appendix A). The colors in the drawings are the familiar colors to the children, i.e. bright yellow, orange, purple, green, red, blue and black.

\subsection{Procedure}

At the onset of my fieldwork, a research assistant helped in my data gathering. I talked out to the parents regarding the intention and objectives of this study. Upon their permission, a video camera was set up to record and document the whole process of the data gathering. I also briefed each child about some instructions. I held up pictures while the RA recorded results. I played and bilingually conversed (Cebuano-English-Cebuano) with each child for familiarization. After becoming familiar with the child we led them to a corner in the house to "play the name game using colored drawings" and subsequently conducted our WOA and ME assumption experiment.

To test my interest on the use of ME in determining parts of familiar and unfamiliar objects in children, I assigned each child to a specific condition. I tested whole-part juxtaposition and $\mathrm{ME}$ as a tool for part term and whole term meaning. To test this, I recreated tests from Markman and Wachtel (1988) in testing ME and from Saylor, Sabbagh, and Baldwin (2006, as cited in Agger, 2009) to decipher use of whole- part juxtaposition.

Children were asked to name the drawing being referred to. In the first condition where the instrument was the drawing of a table with one of the legs as a horse's leg, the child was presented the drawing and asked to identify and name the novel part. The first question was 'What is this?' followed by the second question, 'Is there anything strange or wrong with the table?' Then I introduced an academic 
term of the strange part, which was unfamiliar to the child, and asked the child to point it out. To illustrate the undertaking, Extract 1 is shown below.

\section{Extract 1: $Q \& A$ with Child 3}

Lead Researcher (LR): Kaila ka ani? Unsa man ni? (Do you know this one? What is this?)

Child 3 (C3): Table

LR: Correct! Diri ka answer (You answer here [pointing at the microphone of the video camera].). Table.

C3: Table!

LR: Oh. Correct. What's wrong with the table? Naay sayop sa table. Tudloa. (There's wrong with the table. Point it.)

C3: Pagkaon man na diri sa table. (It's food in the table.)

LR: Oh yes! Pagkaon ang ibutang. Tan-awa sa ang part sa table. Ang iyaang tiil, asa may sayop? (Food is put on the table. Look at the part of the table, which is wrong in its feet?)

C3: Dara (There) [Pointed at the mistake.]

LR: Nganong sayop man na sya, kang kinsa man nang tiil? (Why is this wrong? Whose foot is this?)

C3: Sa horse man na! (It's of the horse's.)

LR: Correct! Sa horse man ni nga tiil. Sus, kaila jud ka noh. (It's the horse's foot. You really know, right?)

C3: O. (Yes.)

The above extract shows the actual conversation with a 3 year-old girl answering the first question about naming what was shown in the drawing. She exactly gave the right answer. As the questioning proceeded, the child added information about the "table" instead of giving her answer for the second question, which urged me to rephrase the question but without necessarily stopping her. One way of appreciating her answer was my affirmation in declarative form, "Oh, yes! Food is put." Then, I directed her attention back to the "table" drawing and repeated "what's wrong with the table?" She pointed at the wrong part "the leg" or "the foot" and told whose foot was it ("the horse's).

It is in the child's naming the correct part (horse's leg) where mutual exclusivity assumption was realized. Every correct answer of the respondent accounted for her ability whether s/he functioned in a mutually exclusive manner or identified the object in whole. Her elaboration at one point of the Q \& A interview indulgently shows the child's ability to expand meaning at the material shown to her, which this study, specifically, excluded. So, I preferred not to indulge her, yet had appreciated her keen sense, in order to keep track with the specific concerns of my work. 


\section{RESULT AND DISCUSSION}

In the study, each experiment with an instrument is taken as a condition. Thus, condition 1 refers to the experiment conducted with the drawing of the table with one of the legs as a horse's leg, condition 2 is the experiment using the picture of the pig whose head has horns of a carabao, condition 3 with the picture of the fish with a lizard's tail, condition 4 with the picture of the butterfly whose other wings are leaves, and condition 5 with the picture of the elephant with a beak attached instead of its long nose and a mouth. Take condition 1. As the experiment is carried out in the way described in the procedure, the expected 'correct' responses are that the child is able to name the whole object, point out the strange part in the object/animal, and point out the right part when the unfamiliar technical term is offered. It is worth mentioning that the criteria 'correct' and 'wrong' are used in a loose sense and only for the purpose of the study.

\subsection{Performance in Condition 1}

Condition 1 is the only experiment using the drawing of an object instead of an animal. The participants' performance in giving the 'correct' and 'wrong' responses is presented in Table 1.

Table 1 Frequency of 'correct' and 'wrong' responses in condition 1 (Drawing: table)

\begin{tabular}{|c|c|c|c|c|c|c|c|c|c|c|c|c|c|c|}
\hline \multirow[t]{2}{*}{ Age } & \multicolumn{4}{|c|}{ Boys } & \multicolumn{4}{|c|}{ Girls } & \multicolumn{4}{|c|}{ Total } & \multirow{2}{*}{\multicolumn{2}{|c|}{$\begin{array}{l}\text { Grand } \\
\text { total }\end{array}$}} \\
\hline & \multicolumn{2}{|c|}{ Correct } & \multicolumn{2}{|c|}{ Wrong } & \multicolumn{2}{|c|}{ Correct } & \multicolumn{2}{|c|}{ Wrong } & \multicolumn{2}{|c|}{ Correct } & \multicolumn{2}{|c|}{ Wrong } & & \\
\hline 4 & 3 & $43 \%$ & 1 & $14.5 \%$ & 3 & $43 \%$ & 0 & $0 \%$ & 6 & $43 \%$ & 1 & $7 \%$ & 7 & $50 \%$ \\
\hline 3 & 2 & $29 \%$ & 1 & 14 & 3 & $43^{c}$ & 1 & 14 & 5 & $36 \%$ & & $14 \%$ & 1 & $50 \%$ \\
\hline Total & 5 & $71 \%$ & 2 & $29.0 \%$ & 0 & $86 \%$ & 1 & $14 \%$ & 11 & $79 \%$ & 3 & $21 \%$ & 14 & $100 \%$ \\
\hline
\end{tabular}

Table 1 shows the performance in the two age groups and two gender groups. First, it is striking that 'correct' responses are predominant in the table. Second, some differences are found when age and gender are taken into account. In the boy group, over 70 percent responses are 'correct', and over 85 percent responses are right in the girl group. In the group of age 4, 'wrong' responses are offered only by boys; in contrast, 'wrong' responses are equally produced by both boys and girls in the group of age 3. Thus, there seems no evidence of a difference in the performance between the gender groups. On the other hand, in the boy group, it seems that the 3year-olds performed similarly to the 4-year-old, as in both groups there is only one participant who gave the 'wrong' responses; in the girl group, only one 'wrong' case is found in the 3-year-olds, and it seems that elder girls performed better than did the younger.

Referring to the participants' verbal performance in the quasi-experiment, results in Table 1 indicate that while whole object assumption still works in children's learning new words mutual exclusivity assumption has overridden the whole object assumption. On the one hand, when asking 'what is this' I only presented the picture to the participants without pointing at any particular part of the table. All the participants gave a direct answer 'it's a table'. Their view of taking the 
table and the horse leg as a whole demonstrates the function of the whole object assumption. When the participants got a novel object (novel because of the strange combination of the table and the horse leg), they tend to take it as one thing instead of two things. If the whole object assumption did not work, the expected answer would be 'it's a table and a horse's leg'. Yet, the unanimous response to the first question verifies that taking things in separate parts is not the view the participants see the world. On the other hand, participants did know that the table and the horse leg were mutually exclusive since they realized that something is wrong or strange with the 'whole' object. When I gave them an unfamiliar technical term of the horse leg and ask them to point it out what the term referred to, their 'correct' responses verify that the participants were using the mutual exclusivity assumption to label the strange leg, since the legs of the table were familiar to them. Thus, the children's performance of taking the table as a whole and their word-learning process of the strange part present the function of the whole object assumption which is overridden by the mutual exclusivity assumption.

Besides, since Table 1 provides no evidence of a significant difference in the performance between the boy group and girl group, it seems that gender may not be a decisive factor in the participant's performance in condition 1. However, age may influence the performance, for elder girls performed better than did the younger.

\subsection{Age}

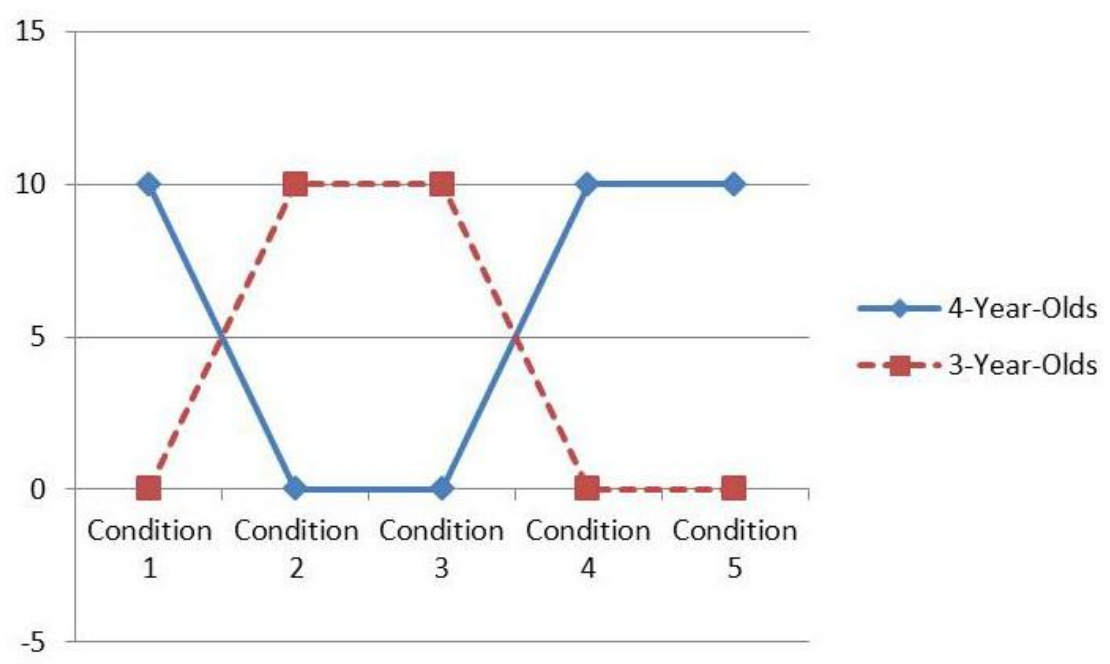

Chart 1. Performance of Age 3 and Age 4 Groups 


\subsection{Gender}

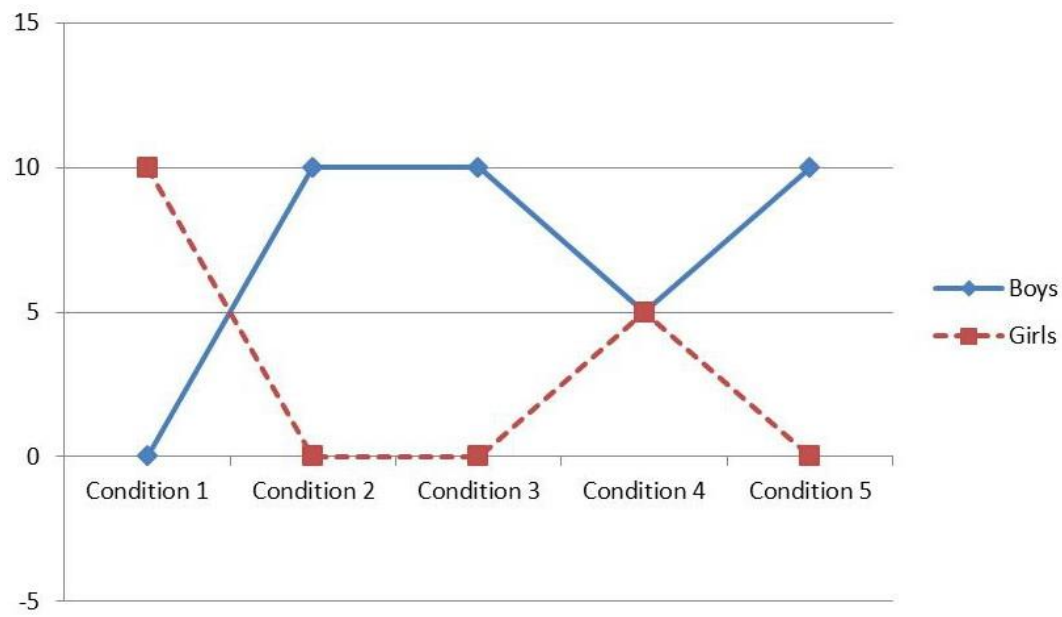

Chart 2. Performance of Boy and Girl Groups

\section{CONCLUSION}

The study investigated the function of WOA and ME assumption in 3-4year-olds in Dipolog City, Philippines. Research findings show that while WOA is still used by the participants, it has been overridden by ME assumption while new labels are presented to the preschoolers at the age of 3 and 4. Further findings reveal no evidence of the claim that older participants used ME better than the younger ones. However, gender seems to play an important role in the participants' performance for boys did much better than girls in the experiments. Thus, the result recommends further future research on the relation between the two constraints on word learning (WOA and ME) and age and gender. However, this study found two limitations: the drawings and the questions used in the study may fail to fully reveal the children's ability since previous studies offer non-standard materials and procedure used in their experiments; and the study itself, is regarded as small-scale. Therefore, the research findings can hardly be generalized. Nevertheless, the research at least presents how the Cebuano speaking preschoolers learned new words via WOA and ME assumption. It is hoped that more research can be generated among the preschoolers in the environment which is quite different from metropolitan Philippine cities such as Manila.

\section{REFERENCES}

Agger, C. (2009). Testing the use of whole-part juxtaposition and mutual exclusivity in preschool children with familiar and non-familiar objects.Indiana Undergraduate Journal of Cognitive Science (4), 36-41. Retrieved on November 20, 2011 from www.cogs.indiana.edu/icogsci/vol4/Children's\%2520Language\%2520Reasonin g.pdf 
Carey, S. (1978). The child as word learner.In M. Malle, J. Bresnan, \& A. Miller (Eds.), Linguistic theory and psychological reality (pp. 264-293). Cambridge, MA: MIT Press.

Clark, E. V. (1983). Meanings and concepts. In J. H. Flavell, \& E. M. Markman (Eds.), Handbook of child psychology: 3. Cognitive development (pp. 787840). New York: Wiley.

Dromi, E. (1987). Early lexical development. Cambridge, MA: Cambridge University Press.

Go, D. I. A. \& Miraflores, E. S. (2009). The effects of joint reference and mutual exclusivity on the application of whole-object assumption in Filipino preschoolers.Philippine ESL Journal (3), pp. 93-111.

Hansen, M, B. \&Markman, E. M. (2009).Children's use of mutual exclusivity to learn labels for parts of objects.Developmental Psychology 45 (2), pp. 592-596.

Markman, E. M. (1990).Constraints children place on word meanings. Cognitive Science, 14, pp.57-77.

Markman, E. M., Wasow, J. L. \& Hansen, M. B. (2003). Use of the mutual exclusivity assumption by young word learners.Cognitive Psychology, 47, pp.241-275.

Xu,F., Cote, M, \& Baker, A. (2005). Labeling guides object individuation in 12month-old infants. American Psychological Society (16)5, pp.372-377. 